\title{
Recognition of Health Care Provider's Patient Safety Culture in Kurdistan/Iraq
}

\author{
Ismail Ahmed Ali \\ Shahid Dr. Aso Hospital \\ Sulaimani General Directorate of Health \\ Ministry of Health \\ Sulaimani, Iraq \\ ismailqaradaxy@gmail.com \\ Shelan Omar Ali \\ College of Nursing \\ University of Raparin \\ Rania, Iraq \\ shilanomer1997@gmail.com
}

\author{
Shewaz Abdalrahman Hussein \\ College of Nursing \\ University of Raparin \\ Rania, Iraq \\ shewaz.kaiwan@gmail.com \\ Fuaad Azad Muhamad \\ College of Nursing \\ University of Raparin \\ Rania, Iraq \\ shaima.azad1422@charmouniversty.org
}

Article Info

Volume 6 - Issue 2-

December 2021

DOI:

10.24017/science.2021.2.14

Article history:

Received 11/10/2021

Accepted 25/1/2022

\section{Keywords:}

Patient Safety, Safety Culture, Health Care Provider,

Kurdistan/ Iraq

\begin{abstract}
Globally, improving and promoting patient safety has been given a lot of attention in order to develop the standard of healthcare and conserve the clients from trauma. The study purposed to recognize the perception of the Health Care Provider (HCP) regarding patient safety culture. A quantitative design /descriptive method was carried out during the period from $12^{\text {th }}$ to $24^{\text {th }}$ January 2019 at Rania teaching hospital. Data was collected through a hard copy self-managed survey form using the Hospital Survey on Patient Safety Culture (HSOPSC). Data was entered in to SPSS and analyzed using descriptive and inferential statistics. The final study sample included 130 cases (74.5\% response rate). The total mean positive answer rate for the hospital survey dimensions was (42.28\%) with a range of (4.6\% - 79\%). Approximately 60\% of HCP was perceived patient safety culture practice negatively. However, only two dimensions from 11 had reached a positive response rate by respondents which include teamwork within units and organizational learning dimensions. While, the frequency of reporting errors dimension had least positive agreement toward PSC. Almost, three fourths of the study sample was indicated that had not reporting events in the previous year. Also, staffs have acknowledged that patient safety grade had in acceptable level in their hospital. Statistically, the results of the study showed a significant association between (educational status, work areas and staff position) and a mean score of HSOPSC $(P<0.05)$. These findings demonstrated that attitudes and perception of HCP about patient safety culture are extremely low. Fundamentally, there is a necessity for systemic change at the level of health organization and continuous training course for $\mathrm{HCP}$ to improve patient safety culture are strongly recommended.
\end{abstract}

Copyright $(02021$ Kurdistan Journal of Applied Research. All rights reserved. 


\section{INTRODUCTION}

The most important domain of healthcare quality in a universal concern is patient safety. Medical mistakes are a vital patient safety concern, due to prolonged hospital lodging, morbidity and death rate, causing an increase in healthcare costs [1]. Nowadays, the health care system is highly complex. Health services frequently are introduced under pressurized circumstances and progress rapidly, due to a diversity of technology and individual decisions and ruling by healthcare staff. Medical mistakes in such an environment could happen [2]. As a result of the diversity in making the error, in an international report by Slawomirski and their colleagues, it is estimated that 10 in every 100 clients is harmed while receiving hospital services in countries with high-income. However, the heaviest burden from adverse events due to mortality and morbidity carry on in countries with low income [3] .

An important part of healthcare quality is Patient Safety Culture (PSC), which could be defined as the general attitude of humans and associations, supported by a shareable group of ideas and ethics that are purposed at minimizing chances for a client's adverse event [4]. The evaluation of a safe environment to protect patients from errors in healthcare organizations is considered to be a first critical step for promoting the quality of health care [5]. Three components of safety culture had been recognized in the literature, containing psychological components, behavioral components, and circumstantial components [6].

Extra awareness had been ordered globally to the subject of patient safety after the liberation of the report "To Err Is Human" in the United States in 1999. The fundamental operator of safety is an organizational culture, which directly affects the safety of healthcare, including values, behaviors, and standard style within institutions. The life-threatening care will persist to happen, in the absence of non-propping the patient safety by the institutional culture [7].

Patient safety culture is influenced by several factors, particularly human-made. The WHO had introduced fundamental descriptions regarding human factors relevant to patient safety including organization and management; Leadership; Teamwork and communication, Managers' and team leadership; Conditions awareness; Accountability and risk management; Stress management; Fatigue and workplace Hazards[8].

Ongoing assessment to identify deficiencies following the areas of patient harmlessness culture starts with measures such as a data-based assessment of the current safety culture and surveys of healthcare staff and leaders on awareness of the commitment to safety issues. Also, a vital point in assessing safety culture is aiding the administrators to realize its effect on the incidence of mistakes. As well provides to recognize common causative risks to mistakes. Protocol management and research survey are reliable methods that contribute to the evaluation of a client's protection culture [9]. However, healthcare services in developed countries involved a several high technological interventions, such as electronic medical records, medication barcoding, and computerized physician order entry systems [10]. This study was purposed to recognize the perception of the HCP's concerning patient safety culture in Raniya district Kurdistan-Iraq.

\section{METHODS AND MATERIALS}

\subsection{Research design and Sample}

The descriptive non-experimental study was carried out from $12^{\text {th }}$ to $24^{\text {th }}$ January 2019 in Rania teaching hospital at Rania district-Kurdistan/Iraq. It involved eight units of the hospital including: emergency, medical ward, surgical ward, laboratory, coronary care unit (CCU), operation room, pharmacy, and radiology unit. The total sample size was taken in the present study is (174) health care providers from both genders.

\subsection{Inclusion and Exclusion criteria}

All participants (medical profession) from both genders in different specialty and facility who take care for patients (directly or indirectly) were included. Managers, administrators, medical students and respondents who disagree to take part in the study were excluded. 


\subsection{Questionnaire design}

The questionnaire consisted of two parts include socio-demographic data \& the "Hospital Survey on Patient Safety Culture (HSOPSC)". The socio-demographic data was designed by the researcher using literature to profit the participant's eligibility. This sheet consists of seven items which include age, gender, level of education, staff position, setting of work, years of employment and type of patient's profession.

The original survey " HSOPSC " was designed by Agency for Health Care Research and Quality [11]. The questionnaire has been translated in to Kurdish language by the researchers and was evaluated by bilingual nursing experts using forward translation [12]. The (HSOPSC) section are made up of 42 open-ended questions that focused on 12 dimensions of safety including: "Teamwork within units; Organizational learning; Management support for patient safety; Overall perceptions of patient safety; Feedback and communication about error; Communication openness; Frequency of event reported; Teamwork across units; Staffing; Handoffs \& transitions; Non-punitive response to errors". Also, the two single questions were associated with the questionnaire regarding errors reported annually and hospital evaluation in relation to patient safety by participants.

\subsection{Questionnaire validity and reliability}

The instrument validity was reviewed by seven experts who have practiced health care professional for more than 10 years from different specialties including (Medicine, Adult nursing, Community health nursing, Maternity, Advanced nursing) related to the field of the study. Their responses indicated that minor changes should be done to a few parts of the instrument tool respectably. The pilot study was executed at Rania teaching hospital sharing (15) health care providers which selected randomly from both genders. It was executed from 20th December to 27th December 2018.

To a large extent, the pilot study indicates that the tool used was clear with little change in some items to expand respondents understanding of the tool. However, the "Director/Leader presumption and activities progressing Patient safety " dimension did not handle accurately by respondents during the process of the pilot study; Therefore, it was excluded from the main research study. The sample of the pilot study was excluded from the main study sample. The Kurdish questionnaire tool's reliability was examined by employing Cronbach's Alpha test. The Split-Half Coefficient was $(r=0.83)$ indicating a good reliable tool in the Kurdish language.

\subsection{Rating and scoring}

To employ the research questionnaire, a Likert scale (five-point) has been used. The study instrument was rated and scored according to author's recommendation: For positively warded items (from one $=$ for Strongly Disagree to Five $=$ for Strongly Agree) scale has been placed. Also, for negatively warded items five-point scales placed as follow: (from Five $=$ for Strongly Disagree to One $=$ for Strongly Agree) .

\subsection{Data collection and analysis}

The purposive sampling was used for this study. A hard copy of the self-administered questionnaire was used to obtain data from participants. After obtaining the oral consent of each respondent the researchers gave instructions to participants on how to deal with the questionnaire. A total of (174) questionnaire was distributed to participants. The final sample size was included made up of 130 participants (response rate: $74.5 \%$ ) in the main study. The whole data was encoded and inserted into Statistical Package for the Social Sciences-version 22 programs for more statistical analysis. Descriptive statistical analysis such as mean, standard deviation, variance, and frequency was employed to summarizing, interpreting data and obtain a percentage of the responses. As well as, inferential statistics examined the association between such variables from demographic characteristic and mean score of the HSOPSC. Cronbach's Alpha (Split-Half Coefficient) test has been applied to examine the internal consistency of the instrument. Almost, a t-test is employed to find out important differences between the means of two groups. Also, in order to identify an association 
between more than two independent variables, Analysis of Variance ANOVA was applied to mark statistical variation.

\section{RESULTS}

From the sample surveyed as shown in Table 1 the participant's mean age was (Mean \pm SD: $33.63 \pm 7.36)$. Also, the majority of respondents were female $(51.5 \%)$ and most of them $(60.8 \%)$ had a diploma. However, the highest $(41.5 \%)$ staff positions participated in this study was institute nurse. As well, the emergency unit proportionally had higher (17.7\%) participation rate. On the other hand, the studied data indicate that the majority $(36.2 \%)$ of the samples had 5-10 years of employment and most of them (90.8\%) acknowledged that they had direct contact with patients.

Table1: Socio-demographic data of the participants

\begin{tabular}{|c|c|c|c|}
\hline Variable & 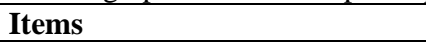 & $\mathbf{F}$ & $\%$ \\
\hline \multirow[t]{4}{*}{ Age groups } & $20-30$ & 52 & 40.0 \\
\hline & $31-40$ & 56 & 43.1 \\
\hline & $41-50$ & 18 & 13.8 \\
\hline & 51 and greater & 4 & 3.1 \\
\hline \multirow[t]{2}{*}{ Gender } & Male & 63 & 48.5 \\
\hline & Female & 67 & 51.5 \\
\hline \multirow{4}{*}{ Level of education } & Postgraduate & 2 & 1.5 \\
\hline & Bachelor's degree & 37 & 28.5 \\
\hline & Diploma & 79 & 60.8 \\
\hline & Secondary school & 12 & 9.2 \\
\hline \multirow[t]{7}{*}{ Staff position } & Physician/physician in training & 9 & 6.9 \\
\hline & College nurse & 17 & 13.1 \\
\hline & Institute nurse & 54 & 41.6 \\
\hline & Secondary nursing school & 12 & 9.2 \\
\hline & Technician (e.g. lab, radiology) & 22 & 16.9 \\
\hline & Pharmacist/ assistants & 4 & 3.1 \\
\hline & Anesthesiologist/ assistants & 12 & 9.2 \\
\hline \multirow[t]{9}{*}{ Setting of work } & Many different hospital units & 4 & 3.1 \\
\hline & Medicine & 20 & 15.4 \\
\hline & Surgery & 15 & 11.5 \\
\hline & Emergency & 23 & 17.8 \\
\hline & $\mathrm{CCU}$ & 18 & 13.8 \\
\hline & Pharmacy & 5 & 3.8 \\
\hline & Laboratory & 18 & 13.8 \\
\hline & Radiology & 4 & 3.1 \\
\hline & Operating room & 23 & 17.7 \\
\hline \multirow[t]{4}{*}{ Years of employment } & less than $5 \mathrm{y}$ & 30 & 23.1 \\
\hline & $5-10$ & 47 & 36.2 \\
\hline & $11-15$ & 19 & 14.5 \\
\hline & 16 and over & 34 & 26.2 \\
\hline \multirow[t]{2}{*}{ Direct contact with patient } & Yes & 118 & 90.8 \\
\hline & No & 12 & 9.2 \\
\hline Total & & 130 & 100 \\
\hline
\end{tabular}

The overall positive response rate for the entire scale as illustrated in Table 2 was $42.28 \%$ ranging from $(1.5 \%$ to $95.4 \%)$. As well as, among the 38 questions that represent patient safety culture dimensions' more than half of the studied items (22question) had not reached the positive response rate by $50 \%$.

The highest positive response rate achieved on this survey $(95.4 \%)$ is within the organizational learning dimension's which worded positively "our staffs are in energetic acting things to progress client safety". However, participants (1.5\%) show a high negative response rate 
concerning the frequency of errors recorded dimension's which mentioned: "when an error is created and could injure the patient, but did not, how frequently is this recorded?".

Table 2: Hospital survey average positive answer rate

\begin{tabular}{|c|c|}
\hline Variable & $\begin{array}{c}\text { Average } \\
\text { positive } \\
\text { response rate } \\
\%\end{array}$ \\
\hline \multicolumn{2}{|l|}{$\begin{array}{l}\text { Hospital work area/unit (18 items) } \\
\text { "Teamwork within units" }\end{array}$} \\
\hline 1. In this department, staff supports each other. & 77.7 \\
\hline 3. As a team, we work together to finish a lot of work rapidly. & 92.3 \\
\hline 4. In this department, the staff respects each other. & 76.2 \\
\hline 11. Other staff helps out when a single area in this department is too busy. & 58.5 \\
\hline \multicolumn{2}{|l|}{ "Organizational learning" } \\
\hline 6. In order to improve patient safety, we are working seriously. & 95.4 \\
\hline 9. Errors have caused appropriate changes over here. & 65.4 \\
\hline 13. Following any changes made to progress client safety, efficacy will be assessed. & 76.2 \\
\hline \multicolumn{2}{|l|}{ "Overall perceptions of patient safety" } \\
\hline 15. To obtain extra work completed, patient safety should not be sacrificed. & 82.3 \\
\hline 18. Our organizations and techniques are perfect at stopping mistakes from incidence. & 68.5 \\
\hline $\begin{array}{l}\text { 10. The further dangerous errors do not occur here merely just by chance. (negatively } \\
\text { worded) }\end{array}$ & 23.8 \\
\hline 17. In our ward, troubles of patient safety exist. (negatively worded) & 12.3 \\
\hline \multicolumn{2}{|l|}{ "Staffing" } \\
\hline 2. Our staff is sufficient to control the workload. & 25.4 \\
\hline $\begin{array}{l}\text { 5. Health care providers in this ward work extra time to supply effective care for } \\
\text { clients. (negatively worded) }\end{array}$ & 9.2 \\
\hline $\begin{array}{l}\text { 7. To supply effective care for clients, we utilize extra non-permanent employees. } \\
\text { (negatively worded) }\end{array}$ & 10.8 \\
\hline 14. We perform a lot of work too fast, as in "crisis mode". (negatively worded) & 2.3 \\
\hline \multicolumn{2}{|l|}{ "Non punitive response to errors" } \\
\hline 8. Employees see their faults are held facing them. (negatively worded) & 17.7 \\
\hline $\begin{array}{l}\text { 12. Following an error is announced, it looks like an individual is being written up, not } \\
\text { the trouble. }\end{array}$ & 26.9 \\
\hline $\begin{array}{l}\text { 16. Employees are concerned regarding errors they create are saved in their own file. } \\
\text { (negatively worded) }\end{array}$ & 67.7 \\
\hline \multicolumn{2}{|l|}{$\begin{array}{l}\text { Communications }(6 \text { items) } \\
\text { "Feedback \& communication about error" }\end{array}$} \\
\hline $\begin{array}{l}\text { 1. Depend on errors reports, our staff receives feedback concerning changes set in the } \\
\text { units. }\end{array}$ & 46.9 \\
\hline 3. Mistakes that occur in our unit we are knowledgeable about. & 53.1 \\
\hline 5. In this ward, we debate methods to overcome mistakes. & 23.1 \\
\hline \multicolumn{2}{|l|}{ "Communication openness" } \\
\hline $\begin{array}{l}\text { 2. Employees will openly speak up whenever catch anything that could impact } \\
\text { patient's care negatively. }\end{array}$ & 42.3 \\
\hline 4. Employees are independent to critique the orders or actions of such administrators. & 38.5 \\
\hline $\begin{array}{l}\text { 6. Employees are scared to inquire about things that do not appear good. (negatively } \\
\text { worded) }\end{array}$ & 52.3 \\
\hline \multicolumn{2}{|l|}{$\begin{array}{l}\text { Your hospital (11 items) } \\
\text { "Management support for patient safety" }\end{array}$} \\
\hline $\begin{array}{l}\text { 1. To progress patient safety, medical institution administrations supplies desired job } \\
\text { environment. }\end{array}$ & 50.8 \\
\hline $\begin{array}{l}\text { 8. Medical institution administrator's activities manifest that client safety is a more } \\
\text { important issue. }\end{array}$ & 69.2 \\
\hline $\begin{array}{l}\text { 9. Medical institution administrators appear concerned about client safety solely } \\
\text { following harmful errors. }\end{array}$ & 25.4 \\
\hline
\end{tabular}




\begin{tabular}{lc}
\hline "Teamwork across units" & 66.9 \\
\hline 4. Medical departments show perfect job collaboration between them as required. & 68.5 \\
\hline $\begin{array}{l}\text { 10. There is work coordination among hospital departments to provide high-quality } \\
\text { care for patients. }\end{array}$ & 30.0 \\
\hline $\begin{array}{l}\text { 2. There is no appropriate collaboration among hospital departments. (negatively } \\
\text { worded) }\end{array}$ & 26.2 \\
\hline $\begin{array}{l}\text { 6. The work with employees with different hospital departments is frequently not } \\
\text { pleasant. (negatively worded) }\end{array}$ & 29.2 \\
\hline "Handoffs \& transitions" & 26.9 \\
\hline $\begin{array}{l}\text { 3. When transporting patients within departments, things "fall between the cracks". } \\
\text { (negatively worded) }\end{array}$ & 28.5 \\
\hline $\begin{array}{l}\text { 5. Between staff rotation, significant data on patient care frequently is lost. (negatively } \\
\text { worded) }\end{array}$ & 25.4 \\
\hline $\begin{array}{l}\text { 7. Numerous problems happen in the interchange of data within hospital departments. } \\
\text { (negatively worded) }\end{array}$ & 3.5 \\
\hline 11. In this hospital, staff rotations are trouble for patients. (negatively worded) \\
\hline "Frequency of events reported" \\
$\begin{array}{l}\text { 1. An error had occurred, however, is cut off and repaired before impacting the client, } \\
\text { how frequently is this recorded? }\end{array}$ \\
\hline $\begin{array}{l}\text { 2. When an error is created but does not injure the patient, how frequently is this } \\
\text { recorded? }\end{array}$ \\
\hline $\begin{array}{l}\text { 3. When an error is created and could injure the patient, but did not, how frequently is } \\
\text { this recorded? }\end{array}$
\end{tabular}

The study results indicated that only two dimensions from 11 had reached positive response rate by respondents which include "organizational Learning" (79\%) and "teamwork within Units" (76.2\%) dimensions. While, the highest deficiencies $(4.6 \%)$ positive response rate of the study sample caught at the area of frequency of events reported dimension figure 1.

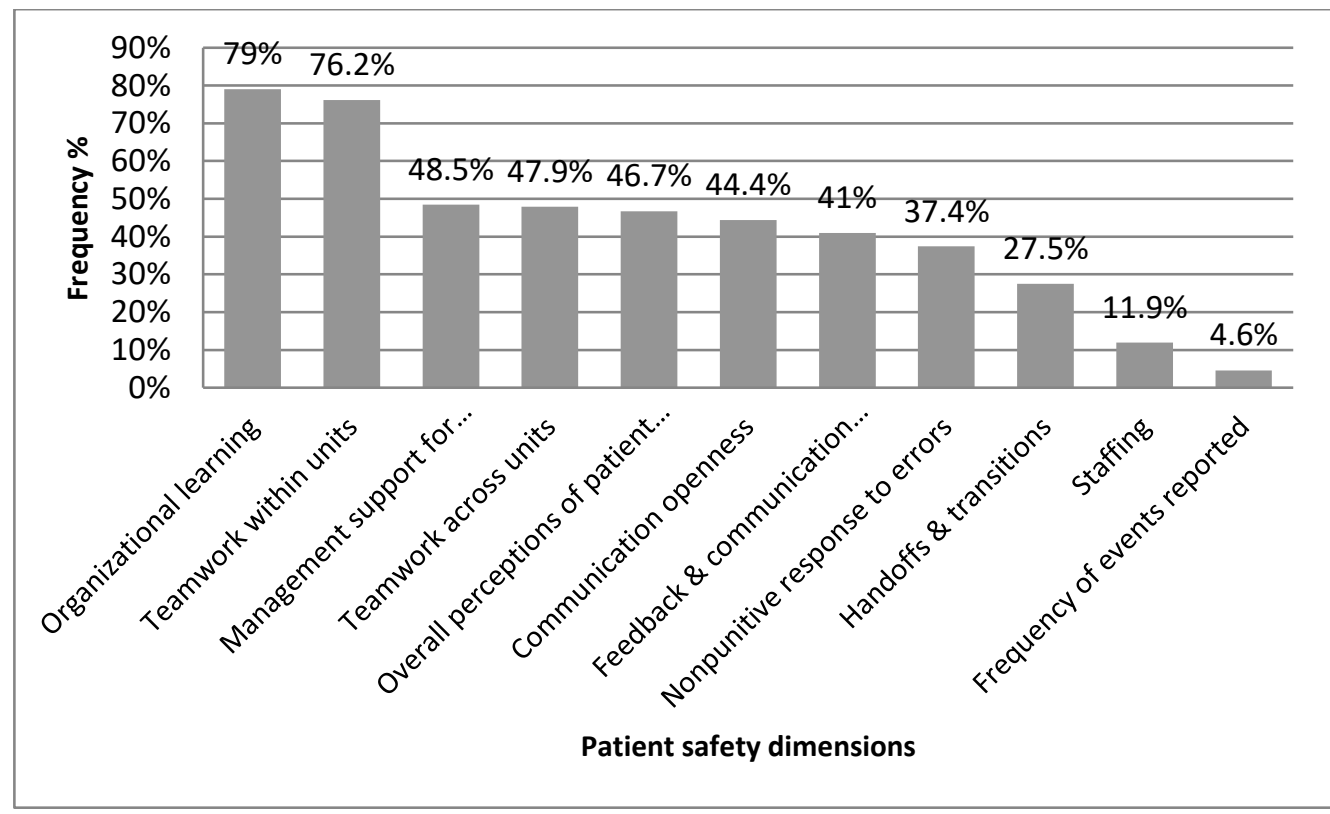

Figure 1: The response rate on patient safety culture dimensions in Rania teaching hospital

Figure 2 shows an illustration of participants' responses to the first question regarding events recording in their work areas. The majority of the study sample $(75.38 \%)$ was acknowledged that no events had reported in the previous twelve months. As well as, the minority of them $(1.54 \%)$ was indicated that only about 5 events were reported in their work area. 


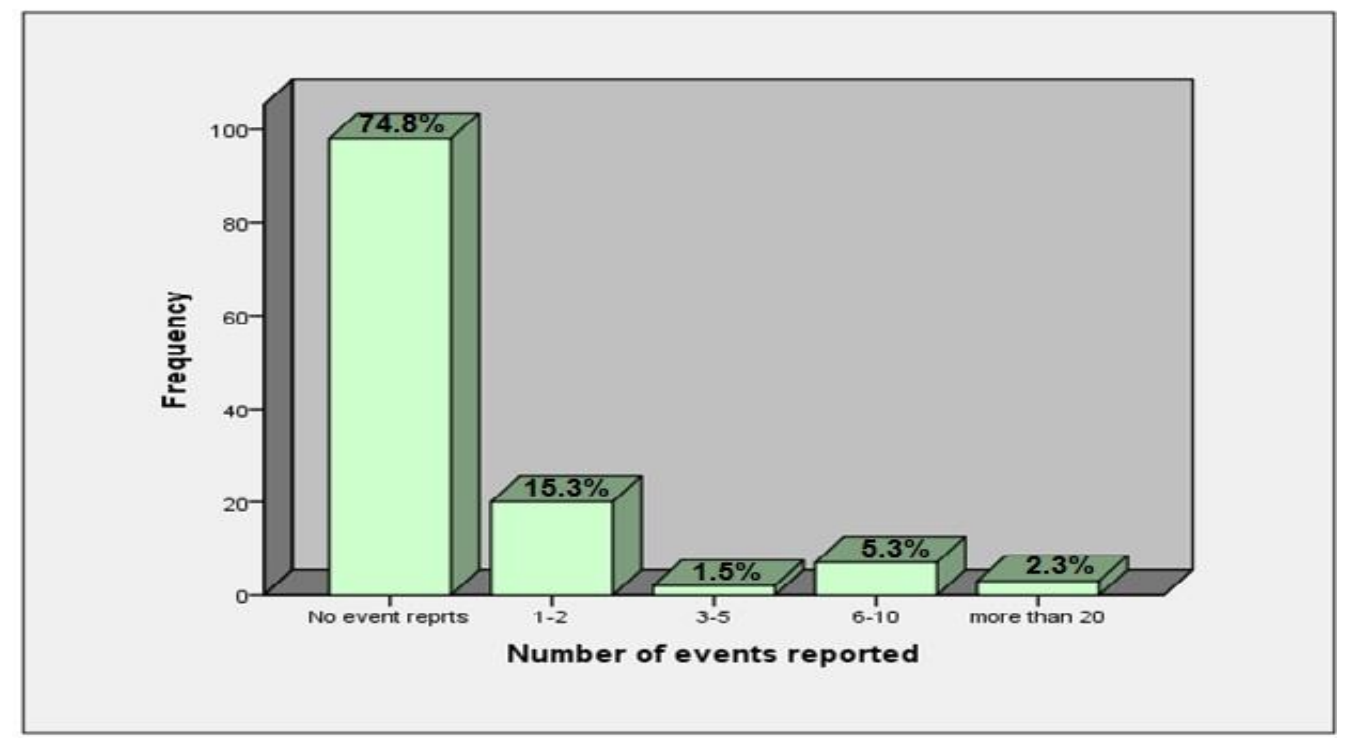

Figure 2: Events recording frequency in work areas

Figure 3 shows an illustration of participants' responses to the second question regarding rating patient safety grades in their hospital. The majority of health care staff $(64.6 \%)$ was agreed that patient safety grades in their hospital had an acceptable level. Also, only (1.6\%) of the study sample graded their hospital as an excellent level in providing patients safety.

The association between the characteristic of the study sample and the mean score of the hospital survey is shown in Table 3. An analysis of variance test statistically indicates no

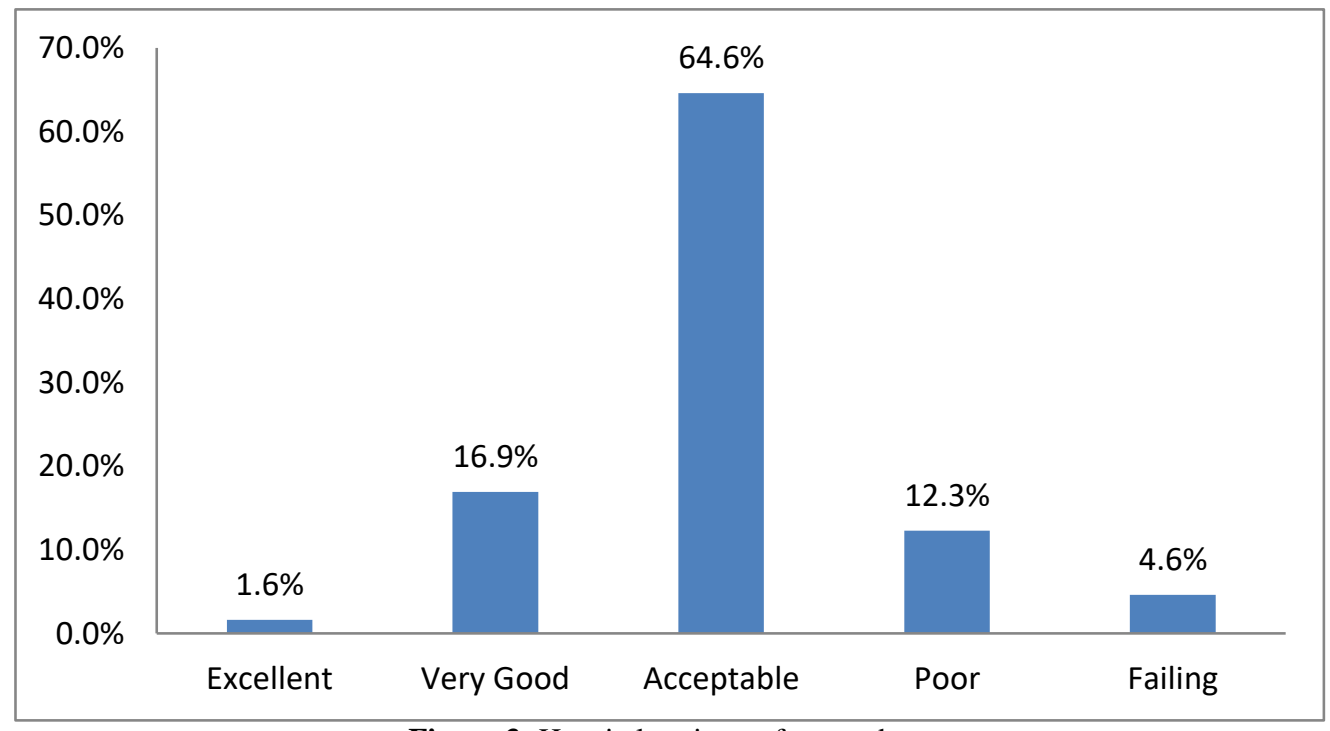

Figure 3: Hospital-patient safety grade

significant relationship in the staff perception regarding PSC among various subgroups such as age groups and years of employment $(\mathrm{p}>0.05)$ by mean score of hospital survey. In addition, an independent t-test statistics do not represent any significant association between men $(\mathrm{M}=3.10, \mathrm{SD}=0.25)$ and women $(\mathrm{M}=3.06, \mathrm{SD}=0.29),(\mathrm{p}=0.473)$. However, the sample 
survey revealed a statistically significant relationship among different work areas, staff position and level of education. HCP who working in many work areas and the emergency unit had a higher score than staff working in the operating room $(\mathrm{p}=0.014)$. Also, in terms of specialty, the institute nurse and secondary nursing school had a higher mean score than college nurse $(\mathrm{p}=0.001)$. Similarly, staff who holding diploma degrees had a higher score than those who holding a postgraduate degree in relation to PSC $(p=0.006)$.

Table 3: Association between the socio-demographic characteristic by mean score of HSOPSC

\begin{tabular}{|c|c|c|c|c|}
\hline Variable & No & Mean & SD & Statistical analysis and P-Value \\
\hline \multicolumn{5}{|l|}{ Age group } \\
\hline $20-30$ & 52 & 3.06 & 0.31 & \multirow{4}{*}{$\begin{array}{c}\text { f: } 0.647 \\
\text { p:0.586 }\end{array}$} \\
\hline $31-40$ & 56 & 3.07 & 0.24 & \\
\hline $41-50$ & 18 & 3.16 & 0.26 & \\
\hline Greater than 50 & 4 & 3.04 & 0.10 & \\
\hline \multicolumn{5}{|l|}{ Gender } \\
\hline Male & 63 & 3.10 & 0.25 & \multirow{2}{*}{$\begin{array}{l}\text { t: } 0.518 \\
\text { p: } 0.473\end{array}$} \\
\hline Female & 67 & 3.06 & 0.29 & \\
\hline \multicolumn{5}{|l|}{ Work Area/Unit } \\
\hline Many different hospital units & 4 & 3.09 & 0.10 & \multirow{9}{*}{$\begin{array}{l}\text { f: } 2.537 \\
\text { p: } 0.014\end{array}$} \\
\hline Medicine & 20 & 3.00 & 0.29 & \\
\hline Surgery & 15 & 3.02 & 0.34 & \\
\hline Emergency & 23 & 3.09 & 0.27 & \\
\hline $\mathrm{CCU}$ & 18 & 2.99 & 0.27 & \\
\hline Pharmacy & 5 & 2.99 & 0.17 & \\
\hline Laboratory & 18 & 3.07 & 0.18 & \\
\hline Radiology & 4 & 2.95 & 0.18 & \\
\hline Operating room & 23 & 2.88 & 0.23 & \\
\hline \multicolumn{5}{|l|}{ Staff position } \\
\hline Physician/physician in training & 9 & 2.99 & 0.09 & \multirow{7}{*}{$\begin{array}{l}\mathrm{f}: 4.193 \\
\mathrm{p}: 0.001\end{array}$} \\
\hline College nurse & 17 & 2.87 & 0.26 & \\
\hline Institute nurse & 54 & 3.11 & 0.28 & \\
\hline Secondary nursing school & 12 & 3.11 & 0.23 & \\
\hline Technician (e.g. lab, radiology) & 22 & 3.05 & 0.18 & \\
\hline Pharmacist & 4 & 3.02 & 0.37 & \\
\hline Anesthesiologists & 12 & 3.32 & 0.26 & \\
\hline \multicolumn{5}{|l|}{ Level of education } \\
\hline Postgraduate & 2 & 2.87 & 0.07 & \multirow{4}{*}{$\begin{array}{l}\text { f: } 4.366 \\
\text { p: } 0.006\end{array}$} \\
\hline Bachelor & 37 & 2.96 & 0.23 & \\
\hline Diploma & 79 & 3.13 & 0.28 & \\
\hline Secondary nursing school & 12 & 3.11 & 0.23 & \\
\hline \multicolumn{5}{|l|}{ Years of employment } \\
\hline less than 5 years & 30 & 3.09 & 0.22 & \multirow{4}{*}{$\begin{array}{l}\text { f: } 2.183 \\
\text { p: } 0.093\end{array}$} \\
\hline $5-10$ & 47 & 3.02 & 0.31 & \\
\hline $11-15$ & 19 & 3.04 & 0.22 & \\
\hline 16 and over & 34 & 3.17 & 0.26 & \\
\hline
\end{tabular}

\section{DISCUSSION}

\subsection{Demographic characteristic}

In the present study, the data analysis regarding age demonstrates that the majority of HCP represent young adult. Proportionally, female participants were representing the major part of the study sample. Also, the majority of the study participant had diploma degree, most of them 
were institute nurses and having about 10 years of experience which approximately acknowledged that had direct contact with the patient.

\subsection{Patient safety culture survey}

Globally, assessment of patient safety in the medical institutions had been increasing demand using HSOPSC which was designed by AHRQ not in Western countries but also in developing countries. Particularly, this request aimed to obtain more knowledge related to patient safety conditions in the present day and to put plans for action concerning this issue in the future.

The sample of 130 respondents from seven units within Rania teaching hospital was assessed. In general, the hospital survey dimension's average positive response was low. However, the areas with high deficiencies among hospital survey include nine dimensions that received the lowest positivity by participants, indicating incredible weakness in practicing patient's protection.

Our results are similar to the studies conducted by researchers from Jordan and Turkey that indicates staff had negative perception toward patient safety culture. whereas Al. Nawafleh and their colleagues in Jordan reported that the total positive awareness was $42 \%$, indicating a lower perception of health care staff concerning PSC [9]. As well as, Bodur and Filiz from turkey acknowledged that the overall patient safety culture score for physician and nurses were lower than the standard score 44\% [13]. However, our results are higher than the mean score of a study conducted by researchers in Egypt that found only $33.3 \%$ of healthcare workers had a positive perception toward patient safety[14].

These outcomes show that health care providers had negative feedback in relation to the culture of patient safety, reflecting the weakness of patient protection from harm. Also, systems and procedures in the hospitals were not adequate in preventing medical errors from happening to the patients. Furthermore, the reasons behind deficiency in patient safety culture among HCP include health management planning, inadequate administrative arrangements, inadequate training courses for staff and geopolitical and economic crisis that faces Kurdistan region in three decades.

Nonetheless, there are a lot of data even in the developing countries indicates that PSC is taken as priority in healthcare delivery system. To a large extent, our results are lower than the data from previous studies done by researchers in (Taiwan, Saudi Arabia, Oman and Iran), which received a higher outcome toward a culture of patient safety. A study via both researchers Chen and Hui Li shows that the average positive reply rate was higher than $60 \%$, indicating that healthcare workers in the Republic of China are feeling confident about patient safety culture within their health institutions [15]. Also, the study result by Alahmadi, indicate that awareness of patient safety among participants had increased and continuing advancement efforts [16]. In addition, Oman's researchers reported that the mean score of HSOPSC was $58 \%$, indicating a positive perception of health care staff toward patient safety culture [17]. Furthermore, our results also are slightly lower as compared to Iranian health staff with positive response rate $(50 \%)$ [18].

The outcome of the present survey detected that HCP attitude toward patient safety in Kurdistan, particularly, within two dimensions are hopeful. A dimension "Organizational learning and group work within departments" was gained a higher positive answer compared to other dimensions of client safety. Our discovery agrees with other work done by the researchers $[19,20]$.

As well as, other studies reported dimension positive scores are low in average regarding patient safety culture $[13,21]$. Nevertheless, the researchers acknowledge great attention and immediate action toward the areas of deficiency such as: First, enhance management support concerning patient's protection; Second, improving culture free from punitive; Third, encourage organizational education; Fourth, focusing on patient transport from one unit to other in the hospital [22].

Furthermore, the "frequency of events reported" dimension has been recorded as the least positive score received than the other dimensions. This is mostly due to the malpractice in medical protocols and not taken the issue of safety as a priority within the medical institutions. 
Also, under-reporting errors may be related to some obstacles such as the legal responsibility of medical malpractice, fearfulness of "blame and punishment", and lack of a universal system that specified and reported mistakes, and who's participates in the recording and relieving the impacts of mistakes [23]. Numerous studies had also declared that not reporting errors is prevalent, especially when the real injury happens [16, 24]. Mistakes could occur at any stage of healthcare service, during an assessment, diagnosis, intervention, monitoring, and even at discharging patients. Almost, before 21 years, the Institute of Medicine acknowledged that "Despite nearly all of the incidents were mostly due to human mistakes. Mistakes are commonly produced by the wrong regulation that lay humans toward faultiness" [5].

In the present study, participants replied to specific question regarding reporting events prior 12 month and patient safety grade. The majority of respondents $(75.6 \%)$ were acknowledged that no events had reports in the previous 12 months and most of them $(64.6 \%)$ rated their hospital as acceptable level. Our findings are consistent with those of other researchers [13, 25]. Otherwise, numerous studies showed less than such outcomes. [4, 26].

\subsection{Association between socio-demographic characteristic}

The study results also revealed that educational status, work areas, and health care provider profession statistically had a greater impact on the culture of patient protection within the hospital. Our findings with respect to education degree indicated that staffs with diploma had higher scores toward patient safety culture rather than bachelor and postgraduate profession. A possible reason could be due to spending more time and effort by diploma participant with patient care, therefore gained more knowledge related to patient safety. Also, nurses within the emergency department had higher scores in comparison to other work settings. The possible reason could be related to that HCP take more training courses in this unit to overcome the different types of trauma and emergency cases related to safety issues. This result is consistent with the study done by Danielsson and their colleagues [27]. However, the present study found no statistical difference between years of employment and mean score of HSOPSC. This result is agreed with the study done by other researchers [28, 29]. On the contrary, some studies have shown that those who had long experience in their profession had higher scores than those with less experience related to the patient safety dimension [14, 30, 31].

\subsection{Limitations}

The current study had some limitations such as time limitations and sample size limitations due to the study was conducted in partial implementation of the demanding for study graduate in of bachelor science in nursing/ College of the Nursing/ University of Raparin.

\section{CONCLUSION}

Kurdish Health Care providers' attitudes and perceptions towards patient safety culture from mistakes have declined, also HCP from different work areas and professions have different attitudes towards patient safety. However, the positivity in perception for the component of group works within departments and systemic learning is hopeful as a starting point to develop patient safety. Fundamentally, there is a necessity for systemic change at the level of health organizations, improve reporting of medical errors, and use of electronic medical records (EMR) within the hospital. Also, in order to promote patient safety, conduct regular assessment, training courses to raise the standard of care are strongly recommended. Moreover, building comprehensive research concerning patient safety culture within HCP in a larger sample size is recommended. 


\section{REFERENCE}

[1] A. Rajalatchumi, T. S. Ravikumar, K. Muruganandham, M. Thulasingam, K. Selvaraj, M. M. Reddy, and J. Balachander "Perception of patient safety culture among health-care providers in a tertiary care hospital, South India," Journal of natural science, biology, medicine, vol. 9, no. 1, p. 14, 2018.

[2] WHO, "World alliance for patient safety: forward programme 2005," World Health Organization, 2004.

[3] L. Slawomirski, A. Auraaen, and N. S. Klazinga, "The economics of patient safety: Strengthening a valuebased approach to reducing patient harm at national level," 2017.

[4] Y. Nie, X. Mao, H. Cui, S. He, J. Li, and M. Zhang, "Hospital survey on patient safety culture in China," BMC health services research, vol. 13, no. 1, pp. 1-11, 2013.

[5] M. S. Donaldson, J. M. Corrigan, and L. T. Kohn, "To err is human: building a safer health system," 2000.

[6] M. D. Cooper, "Towards a model of safety culture," Safety science, vol. 36, no. 2, pp. 111-136, 2000.

[7] L. Palacios-Derflingher, M. O'Beirne, P. Sterling, K. Zwicker, B. K. Harding, and A. Casebeer, "Dimensions of patient safety culture in family practice," Healthcare quarterly, vol. 13, pp. 121-127, 2010.

[8] Ç. Agnew, R. Flin, J. Jackson, and M. Raduma, "Human factors in patient safety: Review of topics and tools: Report to WHO, Geneva," 2009.

[9] A. Al-Nawafleh, M. A. Abu-Helalah, V. Hill, M. I. Masoud, H. A. Al-Mahasneh, and E. T. Al Salti, "Patient safety culture in Jordanian hospitals," Health Science Journal, vol. 10, no. 5, p. 1, 2016

[10] Y. K. Alotaibi and F. Federico, "The impact of health information technology on patient safety," Saudi medical journal, vol. 38, no. 12, p. 1173, 2017.

[11] J. Sorra, L. Gray, S. Streagle, T. Famolaro, N. Yount, and J. Behm, "AHRQ Hospital survey on patient safety culture: User's guide," Rockville, MD: Agency for Healthcare Research Quality, 2016.

[12] W. H. Organization, "Process of translation and adaptation of instruments. nd Retrieved March 4, 2015," ed, 2015.

[13] S. Bodur and E. Filiz, "Validity and reliability of Turkish version of" Hospital Survey on Patient Safety Culture" and perception of patient safety in public hospitals in Turkey," BMC health services research, vol. 10 , no. 1 , pp. 1-9, 2010.

[14] A. Aboul Fotouh, N. Ismail, H. Ez Elarab, and G. Wassif, "Assessment of patient safety culture among health-care providers at a teaching hospital in Cairo, Egypt," 2012.

[15] I.-C. Chen and H.-H. Li, "Measuring patient safety culture in Taiwan using the Hospital Survey on Patient Safety Culture (HSOPSC)," BMC health services research, vol. 10, no. 1, pp. 1-10, 2010.

[16] H. Alahmadi, "Assessment of patient safety culture in Saudi Arabian hospitals," vol. 19, no. 5, pp. e17e17, 2010.

[17] A. Al-Mandhari, I. Al-Zakwani, M. Al-Kindi, J. Tawilah, A. S. Dorvlo, and S. Al-Adawi, "Patient safety culture assessment in Oman," Oman medical journal, vol. 29, no. 4, p. 264, 2014.

[18] S. Azami-Aghdash, F. E. Azar, A. Rezapour, A. Azami, V. Rasi, and K. Klvany, "Patient safety culture in hospitals of Iran: a systematic review and meta-analysis," Medical journal of the Islamic Republic of Iran, vol. 29, p. 251, 2015.

[19] M. A. Blegen, S. Gearhart, R. O'Brien, N. L. Sehgal, and B. K. Alldredge, "AHRQ's hospital survey on patient safety culture: psychometric analyses," vol. 5, no. 3, pp. 139-144, 2009.

[20] M. M. Ghobashi, H. A. G. El-Ragehy, H. M. Ibrahim, and F. A. Al-Doseri, "Assessment of patient safety culture in primary health care settings in Kuwait," Public Health, vol. 11, no. 3, 2014.

[21] A. Q. Jabarkhil, S. S. Tabatabaee, J. Jamali, and J. Moghri, "Assessment of Patient Safety Culture Among Doctors, Nurses, and Midwives in a Public Hospital in Afghanistan," Risk Management Healthcare Policy, vol. 14, p. 1211, 2021.

[22] J. Hellings, W. Schrooten, N. Klazinga, and A. Vleugels, "Challenging patient safety culture: survey results," International journal of health care quality assurance, 2007.

[23] Z. R. Wolf and R. G. Hughes, "Error reporting and disclosure," Patient safety quality: An evidence-based handbook for nurses, 2008.

[24] S. J. Singer, D. Gaba, J. Geppert, A. Sinaiko, S. Howard, and K. Park, "The culture of safety: results of an organization-wide survey in 15 California hospitals," BMJ Quality Safety science, vol. 12, no. 2, pp. 112$118,2003$.

[25] A. Çakır and Ö. Tütüncü, "İzmir ili hastanelerinde hasta güvenliği algısı," Uluslararası Sağlıkta Performans ve Kalite Kongresi, Antalya, TC Sağlık Bakanlı̆̆ Performans Yönetimi ve Kalite Geliştirme Daire Başkanlığl, Ankara, vol. 189, 2009.

[26] J. Kim, K. An, M. K. Kim, and S. H. Yoon, "Nurses' perception of error reporting and patient safety culture in Korea," Western journal of nursing research, vol. 29, no. 7, pp. 827-844, 2007.

[27] M. Danielsson, P. Nilsen, H. Rutberg, and K. Årestedt, "A national study of patient safety culture in hospitals in Sweden," Journal of patient safety, vol. 15, no. 4, p. 328, 2019.

[28] F. El-Jardali, H. Dimassi, D. Jamal, M. Jaafar, and N. Hemadeh, "Predictors and outcomes of patient safety culture in hospitals," BMC health services research, vol. 11, no. 1, pp. 1-12, 2011.

[29] S. A. Park, S. J. Lee, and G. U. Choi, "Survey of factors associated with nurses' perception of patient safety," Asian Pacific Journal of Cancer Prevention, vol. 12, no. 8, pp. 2129-2132, 2011.

[30] A. A. Ammouri, A. K. Tailakh, J. K. Muliira, R. Geethakrishnan, and S. Al Kindi, "Patient safety culture among nurses," International nursing review, vol. 62, no. 1, pp. 102-110, 2015. 
[31] Ü. Y. Güneș, Ö. Gürlek, and M. Sönmez, "A survey of the patient safety culture of hospital nurses in Turkey," Collegian, vol. 23, no. 2, pp. 225-232, 2016. 